\title{
A Rubber Band Ethics Model for Computing and Information Technology Practices
}

\author{
${ }^{1}$ Mahmoud Iskandarani, ${ }^{2}$ Ghaleb El-Refae and ${ }^{3}$ Shorouq F. El-Etter \\ ${ }^{1}$ Faculty of Science and Information Technology, Al-Zaytoonah University of Jordan, Jordan \\ ${ }^{2}$ Faculty of Economics and Administrative Sciences, Al-Zaytoonah University of Jordan, Jordan \\ ${ }^{3}$ Al-Arabia College, P.O.BOX 911597, Post Code: 11191, Amman, Jordan
}

\begin{abstract}
An innovative model for analyzing and describing the role of ethics and the manner in which it is applied in the general field of information technology is presented. Current practices and existing behavior rules that are related to economical and social issues are discussed with specific reference to computing technologies such as the internet. A theoretical model for computing and controlling drifts in ethical practices is then delivered to account for continuously changing socioeconomical factors. The circle-ellipse model used proved to be a new and innovative yet simple way for predicting and analyzing ethics in an ever developing environment.
\end{abstract}

Key words: Ethics, information technology, computers, internet, hacking

\section{INTRODUCTION}

The use of computers and application of Information Technology has affected everyday life and the way people interact with each other. It facilitated certain tasks and opened various doors that could lead to certain undesirable results. As a two sided facility, Information Technology and associated application devices such as computers needed certain guide lines for safe and ethical use ${ }^{[1,2]}$. Religiously based rules such as the following are suggested regarding the use of Information and Computing Technology:

1. Shall not be used to harm people.

2. Shall not affect people's computer work.

3. Shall not violate the privacy of stored files on people machines.

4. Shall not employ computing facilities to commit unauthorized actions.

5. Shall not unlawfully use software to carry out tasks.

6. Shall use computing power and information technology in a considerate and human way with no disrespect to people and social environments under which it operates.

For an increasing number of people, cyberspace is a place they meet new friends and keep in touch with old ones, learn more about hobbies and professions and work for social and environmental change. Electronic bulletin board systems have mushroomed throughout the world, ranging from clubs through hacker underground and on into the bazaar of the great Internet, where philosophers rub shoulders with dropouts and where age, gender and race are only as visible as you want them to be.

Unfortunately, the spectacular growth of cyberspace has not been accompanied by rules for civilized behavior: bullies and criminals swagger electronically through the commons, stealing what they want, breaking what they don't and interfering with decent people's activities. Hence, we must evolve guidelines for civilizing our new frontier ${ }^{[3,4]}$.

The Internet is possibly the most complex and rapidly growing construct humanity has ever created. From the very beginning, it had two simple rules; anyone could say anything; and nothing was official. The current management style of the Internet reflects the belief in unhindered engineering excellence as the best way to find solid solutions for technical problems. This tradition of frank criticism and creativity has been misinterpreted by some newcomers to the Internet as an excuse for frank rudeness and criminality.

In this paper, a Rubber Band model describing various factors that affecting ethical behavior for computer and internet users is presented and described. The model makes use of the elasticity and flexibility of the band to describe how societies' beliefs are affected and sometimes stretched beyond acceptable limits.

Background: Cyberspace is growing fast and the values which inform our lives in physical communities have not yet found their way into cyberspace. Just as in the physical world, unethical, immoral and illegal behavior threatens the agreements that allow people to live and work together in peace.

Many users of cyberspace are well behaved. They are sensitive to nuance, capable of expressive and articulate prose, careful not to hurt feelings and responsible in spreading verified information and not rumor.

However, we also find the cyberspace equivalents of slum lords, drug pushers, boors and bully boys. There are people running private bulletin boards, Web

Corresponding Author: Mahmoud Iskandarani, Faculty of Science and Information Technology, Al-Zaytoonah University of Jordan, Jordan 
sites that cater to thieves, drug users, Nazis and pedophiles. People who might never think of insulting a stranger to her face write nasty and juvenile notes.

Different service providers adopt different stances about the content of communications on their network. At the other extreme, there are networks, Forums and Websites where anarchy reigns. Contributions are unfiltered, unfettered, frequently ungrammatical and sometimes illegal. Some boards and groups pander to unusual sexual orientations, with hundreds of pornographic text and picture files available online. Others specialize in stolen or malicious software and instructions on picking locks, stealing services and building bombs ${ }^{[5,6]}$.

Such rude, unethical, immoral and illegal behavior puts the entire Net at risk from self appointed as well as legally delegated guardians of public morality and corporate interests. Examples of faced problems are:

1. Some criminals use control codes or special tone to steal telephone services.

2. Voice mail subversion is another tactic used by phone criminals Voice mail systems allow callers to leave messages for specific employees.

3. A problem caused by hackers is the loss of confidence in system integrity.

4. Credit records are relatively easy for criminal hackers to find, although it's much harder to modify them.

5. Industrial espionage is growing especially across international borders.

6. Malicious software such as viruses, worms, Trojan Horses and logic bombs.

7. The most widespread computer crime is software theft

The rubber band model: Ethical theorizing begins when we think about how we ought to live. Many people assume that means we must look for moral criteria: some list of rules or principles whereby we can distinguish good from bad and right from wrong, or a list of virtues we try to inculcate. Utilitarian tell us we should promote the greatest happiness of the greatest number. We should look for the criteria emerging from a real or hypothetical agreement. We should treat others as "ends in themselves" and not as mere means. Divine Command theorists tell us to follow the commands of $\operatorname{God}^{[7,8]}$.

In this work, the suggested criterion for acceptable ethical and moral behavior is represented by a circle. This circle (Rubber Band) encompasses the society we are living in with all its cultural differences enclosed and represented by two parameters:

1. The location of the circle with respect to center point that represents default social stability and its ability to shift and interfere with other societies after being itself affected by external factors.
2. The overall area of the circle with its power to reach and affect other circles in the vicinity if affected by external factors.

Figure 1 shows a standard circle (Rubber Band) that could be used to represent any chosen society with various clusters of factors resulting from the use of cyberspace or the internet. Such clusters are trying to influence the position and shape of the band with actions illustrated in Table 1.

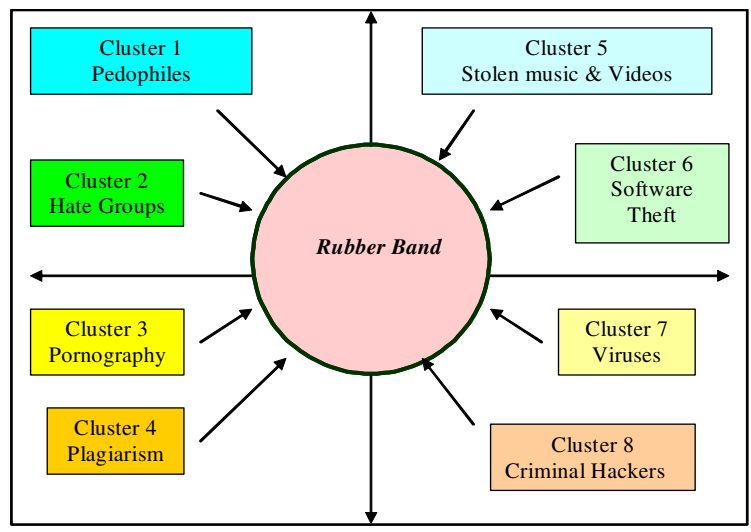

Fig. 1: Clusters affecting the rubber band representation

Table 1: Clusters and their actions

\begin{tabular}{|c|c|}
\hline Cluster & Details \\
\hline Pedophiles & $\begin{array}{l}\text { - Misrepresentation as youngsters } \\
\text { - Chat rooms } \\
\text { - E-mail } \\
\text { - Video films } \\
\text { - Bus/Airline tickets - meetings }\end{array}$ \\
\hline Hate Groups & $\begin{array}{l}\text { - Growing movements across } \\
\text { world } \\
\text { - Anti-everything } \\
\text { - Recruiting young people through } \\
\text { Web }\end{array}$ \\
\hline Pornography & $\begin{array}{l}\text { - Widespread - massive content } \\
\text { - Misleading URLs } \\
\text { - Junk e-mail invitations }\end{array}$ \\
\hline Plagiarism & $\begin{array}{l}\text { - Buy / trade copies of essays, } \\
\text { papers }\end{array}$ \\
\hline Stolen Music \& Video & $\begin{array}{l}\text { - Trading copies of music most } \\
\text { without } \\
\text { permission }- \\
\text { violations }\end{array}$ \\
\hline Software Theft & $\begin{array}{l}\text { - Stolen software } \\
\text { - violation of copyright law }\end{array}$ \\
\hline Viruses & $\begin{array}{l}\text { - Self-replicating code } \\
\text { - program infectors } \\
\text { - boot-sector viruses } \\
\text { - Internet-enabled worms } \\
\text { - Non-replicating code: Trojan } \\
\text { horse } \\
\text { - Sources } \\
\text { - deliberate infection } \\
\text { - virus-exchange sites }\end{array}$ \\
\hline
\end{tabular}

Resulting actions from such clusters are impacting societies and penetrating their very much protected fiber with different depths and consequences ${ }^{[9,10]}$. 


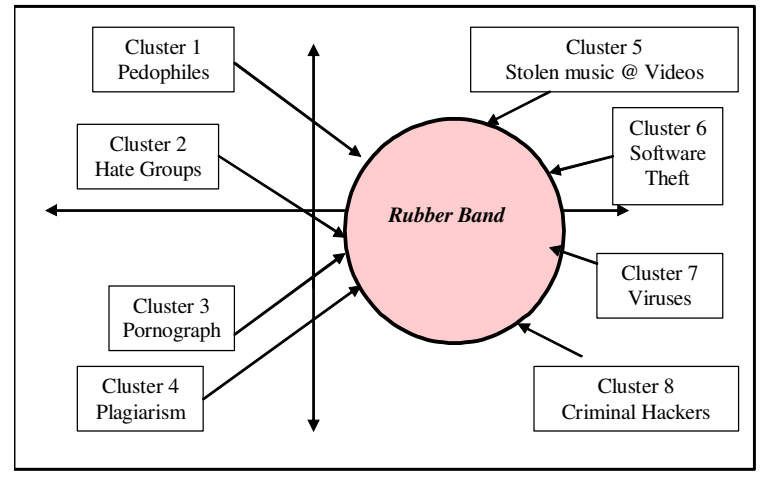

Fig. 2: Displaced rubber band of ethics (circle)

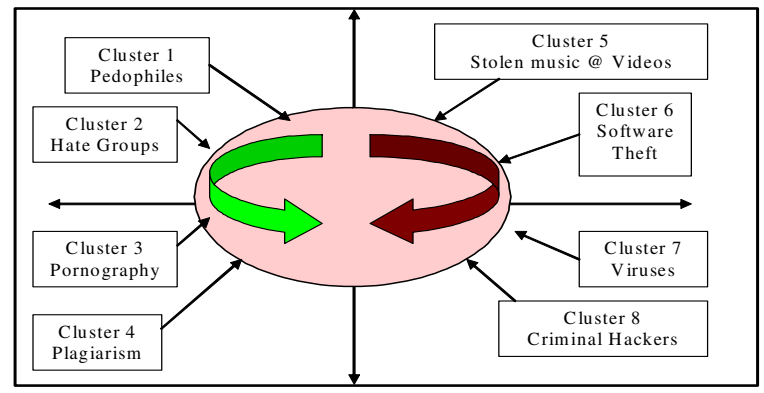

Fig. 3: Penetrated rubber band of ethics (ellipse)

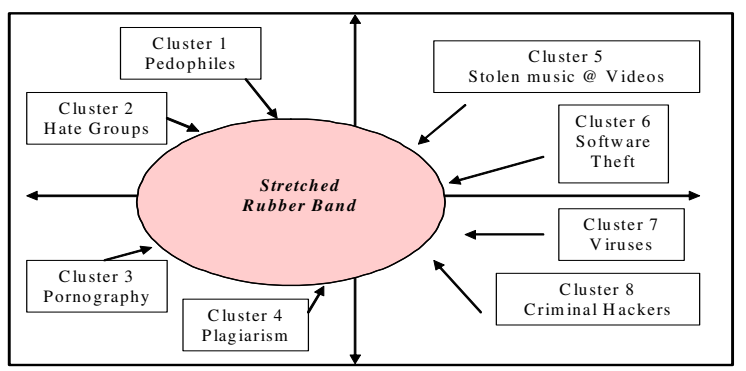

Fig. 4: Penetrated and displaced rubber band of ethics (ellipse)

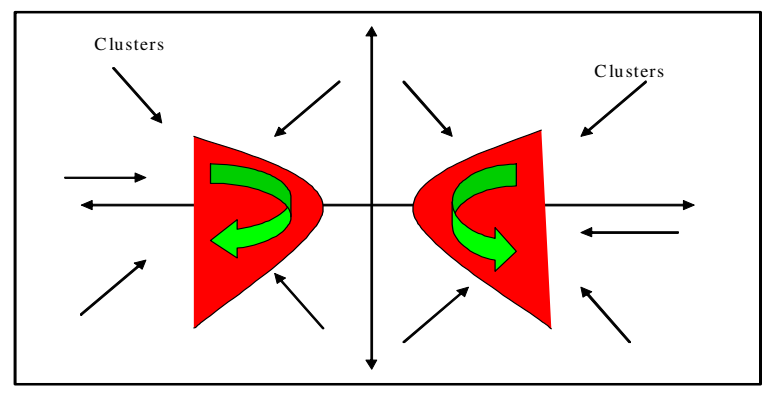

Fig. 5: Ruptured rubber band of ethics (hyperbola)

Such penetrations are multiplying inside the social fiber represented here by a circle, which also represents the shape of a simple Rubber Band. Consequently, such clusters would start to disintegrate beliefs and moralities within the society and would of course be face with pockets of resistance. Having the circle acting as a Rubber Band with such pressurizing factors would lead to either of two results as mentioned above and presented in Fig. 2 and 3. Figure 2 illustrates the shifting effect such factors could have on society ethics and behavior, which could end the Band anywhere within the four coordinates.

The clusters are now inside and continuously trying to change the society with its beliefs and practices. At the same time, more factors are arriving over time from the outside. The newly arrived factors would have less resistive structure to penetrate, as they would encounter what is called friendly forces inside, hence an elliptical form of the Rubber Band is witnessed due to summation of factors. As such activities continue and over a period of time, we would expect in certain societies and certain areas of a society to evolve out of their original moral and ethical commitments and the Rubber Band to either shift in position due to destabilization and moves to a new location as shown in Fig. 4, or change shape yet again if pressure exceeds its threshold and form a hyperbolic shape as shown in Fig. 5.

Mathematically, there are well known equations that relate circle to ellipse to hyperbola as follows ${ }^{[11,12]}$.

I. Circle: $\quad(x-h)^{2}+(y-k)^{2}=r^{2}$ (Where $\mathrm{h}$ and $\mathrm{k}$ are the $\mathrm{x}$ - and $\mathrm{y}$-coordinates of the center of the circle and $\mathrm{r}$ is the radius).

II. Ellipse: $(x-h)^{2} / a^{2}+(y-k)^{2} / b^{2}=1$ (Where $\mathrm{h}, \mathrm{k}$, $\mathrm{a}$ and $\mathrm{b}$ are real numbers. $\mathrm{a}$ and $\mathrm{b}$ are positive).

III. Hyperbola: $x^{2} / a^{2}-y^{2} / b^{2}=1$ (Where $\mathrm{a}$ and $\mathrm{b}$ are positive real numbers).

To prove the intimate relationship between the previously suggested models, the relationship between the three mathematical shapes is investigated. In the standard ellipse equation, the length ' $a$ ' is half the long axis of the ellipse and ' $b$ ' is half the short axis

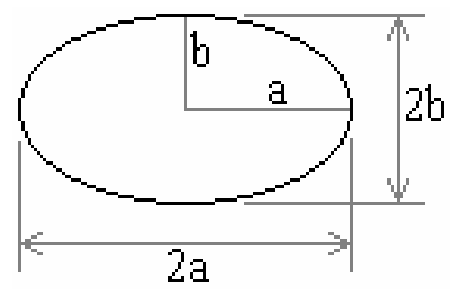

If $\mathrm{a}$ and $\mathrm{b}$ are equal, we have a circle with:

$\mathrm{a}=\mathrm{b}=$ radius of circle

$\mathrm{e}=0$ (eccentricity is zero)

For an ellipse that is not a circle:

$\mathrm{a}>\mathrm{b}$

$0<\mathrm{e}<1$

$a$ is greater than $b$ and the eccentricity is between 0 and 1.

The canonical form of the ellipse equation is:

$\frac{x^{2}}{a^{2}}+\frac{y^{2}}{b^{2}}-1=0$

That is an ellipse which is not rotated or translated (has center at the origin). Any ellipse can be broken down into that form through rotation and/or translation. 


\section{Eccentricity}

$$
e=\sqrt{1-\frac{b^{2}}{a^{2}}}
$$

Parametric Equations

$\mathrm{x}=\mathrm{a} * \cos (\mathrm{t})$

$\mathrm{y}=\mathrm{b} * \sin (\mathrm{t})$

Parametric Equations for Polar Coordinates (with pole at center of ellipse):

$$
\begin{gathered}
\mathrm{x}=\mathrm{r} \cos \theta \quad \mathrm{y}=\mathrm{r} \sin \theta \\
\mathrm{r}=\frac{\mathrm{b}}{\sqrt{1-\mathrm{e}^{2} \cos ^{2} \theta}}
\end{gathered}
$$
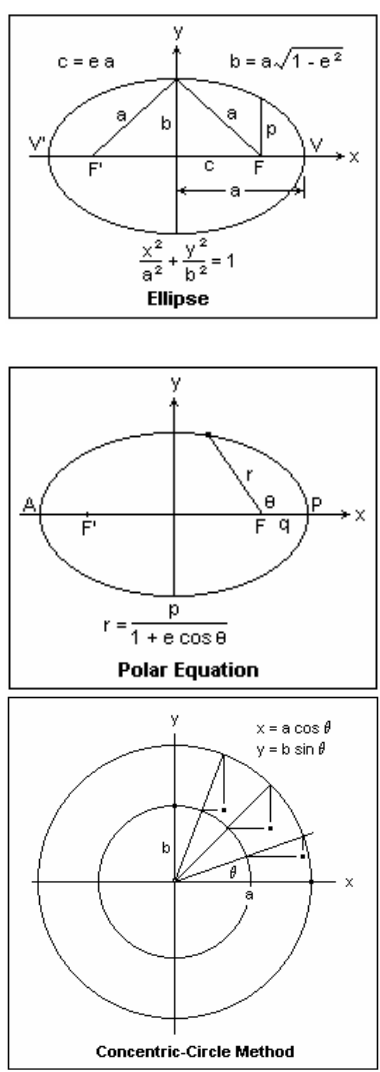

An ellipse is the intersection of a cylinder and a plane. In other words, an ellipse is the projection of a circle.

Proof: Suppose we have a circle on the XY plane, with the center of the circle at the origin $(0,0)$. Also assume we have a point on the circle, in the first quadrant of the $\mathrm{XY}$ plane. Further assume there is a tilted plane intersecting the $\mathrm{XY}$ plane along the $\mathrm{Y}$ axis and that on this tilted plane is the image of the circle parallel projected in the $\mathrm{Z}$ direction, as shown here:

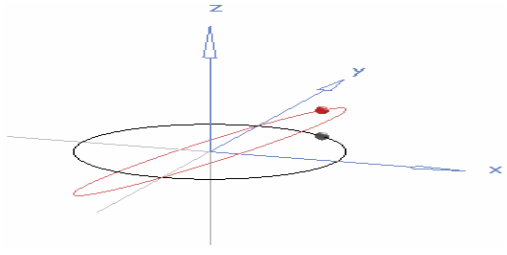

All points on the red ellipse are directly above or below the black circle, in the $\mathrm{Z}$ direction. The point on the circle is directly below the point on the ellipse.

You can imagine the red ellipse is the intersection of the tilted plane with a cylinder running along the $\mathrm{Z}$ axis. That is, the cylinder has the $Z$ axis as its axis of symmetry. And the cylinder intersects the XY plane at the black circle.

If you look straight down at the XY plane, the ellipse appears as a circle directly above and below the black circle:

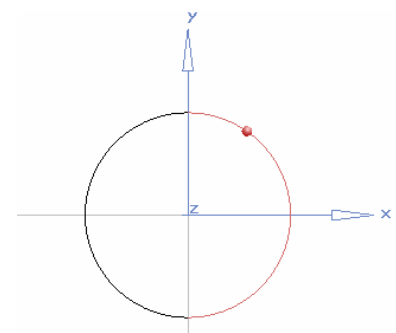

We define ' $r$ ' as the radius of the circle and (i,j) as the XY coordinates of the point on the circle:

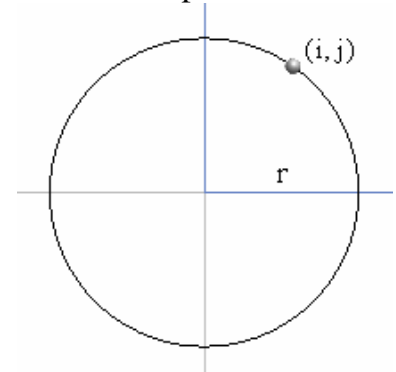

Next we will look at the ellipse from the direction perpendicular to its plane. That is, we look at the ellipse straight down its own $\mathrm{Z}$ axis, not from the direction of any of the axes shown in the graphs above. Here is that view (at a smaller scale than the previous circle view):

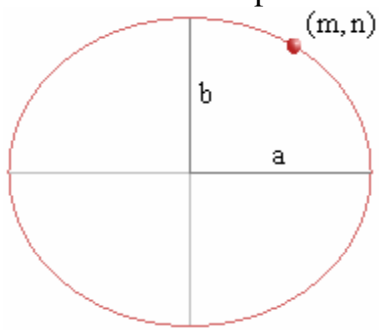

That is the ellipse in canonical position. The plane of the ellipse intersects the circle plane along the Y axis. That is, both the circle and ellipse have the same $\mathrm{Y}$ axis. The constant ' $\mathrm{b}$ ' of the ellipse is equal to the circle radius ' $r$ ': $b=r$

The constant ' $a$ ' of the ellipse is: $a=r / \cos \emptyset$ ( $\varnothing$ is the tilt angle between the planes).

Since the circle and ellipse have the same $\mathrm{Y}$ axis, the point on the ellipse has the same Y coordinate as the point on the circle: $n=j$

To find the relation between the $\mathrm{X}$ coordinates of the two points, we look at the ellipse and circle from the negative $\mathrm{Y}$ direction of the circle plane: 


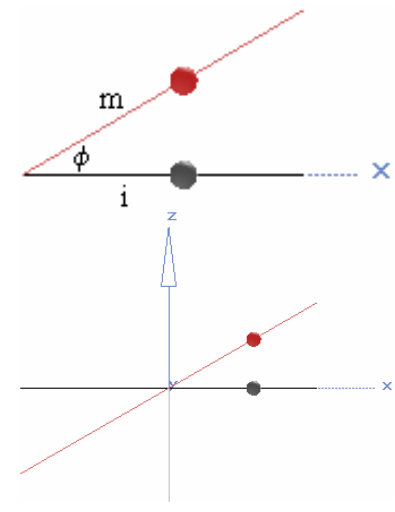

Using trigonometry: $\mathrm{m}=\mathrm{i} / \cos \emptyset$

The standard equation of an ellipse in canonical position is: $\left(\mathrm{x}^{2} / \mathrm{a}^{2}\right)+\left(\mathrm{y}^{2} / \mathrm{b}^{2}\right)=1$

Substituting $(\mathrm{m}, \mathrm{n})$ for $(\mathrm{x}, \mathrm{y}):\left(\mathrm{m}^{2} / \mathrm{a}^{2}\right)+\left(\mathrm{n}^{2} / \mathrm{b}^{2}\right)=1$ As mentioned above $b=r$ so substitute $r$ for $:\left(\mathrm{m}^{2} / \mathrm{a}^{2}\right)$ $+\left(n^{2} / r^{2}\right)=1$

Since $m=i / \cos \emptyset$ and $a=r / \cos \varnothing$, we obtain $:\left(i^{2} \cos ^{2} \varnothing\right.$ / $\left.\mathrm{r}^{2} \cos ^{2} \varnothing\right)+\left(\mathrm{n}^{2} / \mathrm{r}^{2}\right)=1$

The $\cos ^{2} \varnothing$ terms cancel out: $\left(\mathrm{i}^{2} / \mathrm{r}^{2}\right)+\left(\mathrm{n}^{2} / \mathrm{r}^{2}\right)=1$

As noted above $n=j$ so substitute $j$ for $n:\left(i^{2} / r^{2}\right)+\left(j^{2} /\right.$ $\left.\mathrm{r}^{2}\right)=1$

Then multiply both sides of the equation by $r^{2}: i^{2}+j^{2}=r^{2}$

That is true according to the Pythagorean Theorem and is equivalent to the equation of the circle.

Using the theorem again, we can derive a Hyperbola from a circle. However, by doing this the circular functions are transformed into hyperbolic ones. This further supports our presented models as the relationship within the model changes in nature and direction.

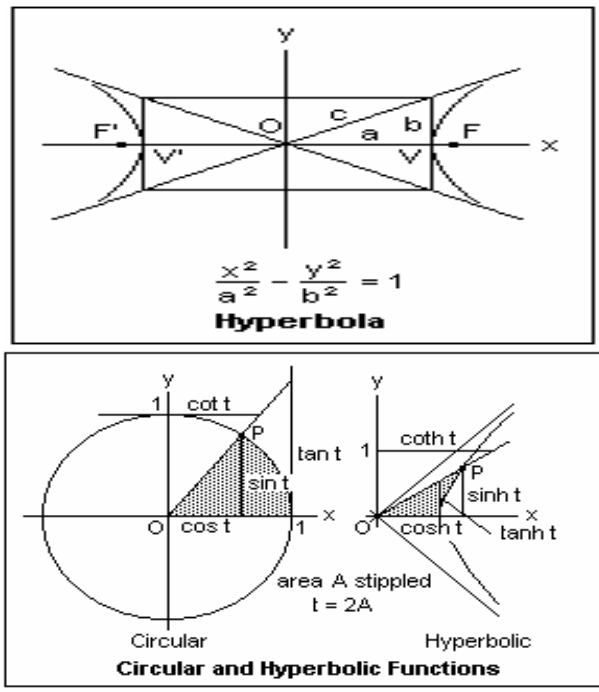

\section{DISCUSSION AND CONCLUSION}

It takes time to integrate morality into our technological universe, so, we need a consensus on good behavior in cyberspace.
Criminal hackers who break into computer systems and roam through users' private files should be viewed as Peeping Toms. Criminals using computers to extort money or steal services should be recognized as thieves. Those who destroy records, leave logic bombs and write viruses should be viewed as vandals. Hackers who smear obscenities in source code should be seen as twisted personalities in need of punishment and therapy $^{[13,14]}$.

We need to discuss the immorality of virus writing, the ethical implications of logic bombs and the criminality of electronic trespassing. We should teach children how to be good citizens of cyberspace - and not just in schools. We should sit down with computer using youngsters and follow them through their adventures in cyberspace. Parents should ask their teenaged whiz kids about hacking, viruses, software theft and telephone fraud. We must bring the perspective and guidance of adult generations to bear on a world that is evolving faster than most of us can imagine. We need to stop listening to illogical excuses made by unethical people, such as the following regarding software theft:

1. Everyone's doing it.

2. We won't get caught.

3. It's software industry's fault: if they don't want theft, they should charge less.

4. It's the company' fault: if they don't want theft, they should make it technically impossible.

5. It doesn't hurt anyone.

6. It only hurts a company - I wouldn't steal it from an individual.

7. The industry is violating the rights of the programmers, so breaching copyright is a Good Thing.

8. Our theft is helping the software industry increase their sales.

9. No software should ever be copyrighted - it should always be free.

10. But I need it and I don't want to pay for it.

To return the Rubber Band to its default circular form, monitoring and filtering of the cyberspace contents are necessary as a parallel step to good upbringing of people. Such process includes:

1. Tools for reviewing what users are doing on the Net such as Audit trails, disk files, browser URL trail, browser disk cache, anti-virus products, antigame software, anti-MP3-music software, real-time alerts, web page, suspect e-mail content, human inspection, remote-access software, supervising by walking around.

2. Tools for limiting what users are doing on the Net such as Anti-virus products, Firewalls, Self-rating $\&$ filtering proposals, Censorware

Overall, the discussed Rubber Band model succeeded in presenting changes in society's ethics due to outside interference. The factor of persuasion plays 
an important role in all of what is discussed. In addition, a different way of upbringing and education should be implemented to counter many of the witnessed degradation in ethical values ${ }^{[15,16]}$.

\section{REFERENCES}

1. Grodzinsky, F.S., 2000. The development of the 'ethical' ICT professional: and the vision of an ethical on-line society: How far have we come and where are we going? ACM SIGCAS Computers and Society, 30: 3-7.

2. Reynolds, C. and R. Picard, 2004. Affective sensors, privacy and ethical contracts. Conf. Human Factors in Computing Systems, Austria, pp: 1103-1106.

3. Fogg, B., 1998. Persuasive Computers: Perspectives and Research Directions. Proc. SIGCHI Conf. Human factors in computing systems, pp: 225-232, Addison-Wesley Publishing.

4. Spinello, R.A. and T.T. Herman, 2001. The internet, ethical values and conceptual frameworks: an introduction to Cyberethics. ACM SIGCAS Computers and Society, 31: 5-7.

5. Aley, E, T. Cooper, R. Graber, A. Kerne, K. Overby and Z. Toups, 2005. Exploring censorship and social presence through psychophysical sensing. Proc. 13th Ann. ACM Intl. Conf. Multimedia, Nov. 6-11, Singapore.

6. Prior, M., S. Rogerson and B. Fairweather, 2002. The ethical attitudes of information systems professionals: outcomes of an initial survey. Telematics and Informatics, 19: 1.
7. Towell, E., J. Thompson and K. McFadden, 2004. Introducing and developing professional standards in the information systems curriculum. Ethics and Information Technology, 6: 291-299.

8. Miller, K., 2005. How good is good enough?: An ethical perspective informed by technical knowledge. J. Comput. Sci. in Colleges, 21: 5-6.

9. Mancherjee, K. and A. Sodan, 2004. Can computer tools support ethical decision making? ACM SIGCAS Computers and Society, 34: 1.

10. Davison, R., 2002. Ethics and research methods. Proc. 35th Ann. Hawaii Intl. Conf. System Sciences (HICSS'02), 8: 253.

11. http://www.3dsoftware.com /Math/Plane Curves/ EllipseAlgebra/

12. http://www.du.edu/ jcalvert/math/hyperb.htm

13. Sukhai, N., 2004. Hacking and cybercrime. Proc. 1st Ann. Conf. Information Security Curriculum Development, Georgia, pp: 128-132.

14. Waller, B., 2005. You Decide! Current Debates in Ethics. Longman Publishing Group.

15. Alzari, R., 2005. Current Security Management and Ethical Issues of Information Technology. Ideal Group Publishing.

16. Bittner, P. and E. Hornecker, 2005. A micro-ethical view on computing practice. Proc. 4th Decennial Conference on Critical Computing: Between Sense and Sensibility, Denmark, pp: 69-78. 